\title{
Neurosurgery Simulators Developed for Neurosurgical Training in Brazil: A Systematic Review
}

\section{Simuladores de neurocirurgia desenvolvidos para o treinamento neurocirúrgico no Brasil: Revisão sistemática da literatura}

\author{
Bernardo Drummond-Braga ${ }^{1,3}$ Nayara Matos Pereira ${ }^{2}$ João Henrique Vieira Pedroso ${ }^{3}$ \\ Vinicius da Silva Oliveira ${ }^{3}$ Marcelo Ribeiro da Rocha ${ }^{3}$ Lucas Wilson Matos Gomes ${ }^{3}$ \\ Mariana Vieira Martins Sampaio Drummond ${ }^{1}$ Ana Luiza Morais Avelar Drummond ${ }^{1}$ \\ Marcelo Magaldi Ribeiro Oliveira ${ }^{4}$ Marco Tulio Antonio Garcia-Zapata ${ }^{3}$
}

\footnotetext{
1 Department of Neurosurgery, Instituto de Neurologia de Goiania, Goiânia, GO, Brazil

${ }^{2}$ Department of Neurosurgery, Hospital Geral de Goiânia, Goiânia, GO, Brazil

${ }^{3}$ Faculty of Medicine, Universidade Federal de Goiás, Goiânia, GO, Brazil

${ }^{4}$ Department of Surgery, Universidade Federal de Minas Gerais, Belo Horizonte, MG, Brazil
} Address for correspondence Bernardo Drummond-Braga, MD,
Instituto de Neurologia de Goiânia, Goiânia, GO, Brazil
(e-mail: bernardodrummond@yahoo.com.br).

\begin{abstract}
Keywords

- simulation training

- neurosurgery

- spine

- education

- Brazil

Introduction Simulation in neurosurgery is a growing trend in medical residency programs around the world due to the concerns there are about patient safety and the advancement of surgical technology. Simulation training can improve motor skills in a safe environment before the actual setting is initiated in the operating room. The aim of this review is to identify articles that describe Brazilian simulators, their validation status and the level of evidence (LoE).

Methodology This study was conducted using the Preferred Reported Items for Systematic Reviews and Meta-Analysis (PRISMA) guidelines. A search was performed in the Medline, Scielo, and Cochrane Library databases. The studies were evaluated according to the Medical Education Research Quality Instrument (MERSQI), and the LoE of the study was established according to the classification system of the Oxford Centre for Evidence-Based Medicine (OCEBM), which has been adapted by the European Association of Endoscopic Surgery.

Results Of all the studies included in this review, seven referred to validated simulators. These 7 studies were assigned an average MERSQI score of 8.57 from 18 possible points. None of the studies was randomized or conducted in a high-fidelity environment. The best evidence was provided by the studies with the human placenta model, which received a score of $2 b$ and a degree of recommendation of 3 .
\end{abstract}

received

May 16, 2019

accepted

July 1,2019
DOI https://doi.org/

10.1055/s-0039-1696708. ISSN 0103-5355.
Copyright $\odot 2019$ by Thieme Revinter

Publicações Ltda, Rio de Janeiro, Brazil
License terms

(c) (1) $\ominus$ (\$) 


\section{Resumo}

\author{
Palavras-chave \\ - treinamento de \\ simulação \\ - neurocirurgia \\ - espinha \\ - educação \\ - Brasil
}

\begin{abstract}
Conclusion Brazilian simulators can be reproduced in the different laboratories that are available in the country. The average MERSQI score of Brazilian studies is similar to the international average score. New studies should be undertaken to seek greater validation of the simulators and carry out randomized controlled trials.
\end{abstract}

Introdução A simulação em neurocirurgia é uma tendência crescente em programas de residência médica em todo o mundo devido às preocupações que existem sobre a segurança do paciente e o avanço da tecnologia cirúrgica. O treinamento com simulação permite aprimorar as habilidades motoras em um ambiente seguro antes de partir para o cenário real na sala de cirurgia. O objetivo desta revisão é identificar artigos que descrevam simuladores brasileiros, determinar o status de validação e nível de evidência (LoE).

Metodologia Esse estudo foi realizado utilizando o Preferred Reported Items for Systematic Reviews and Meta-Analysis (PRISMA) guidelines. Foi realizado uma busca nas bases de dados Medline, Scielo e Cochrane. Os estudos foram avaliados de acordo com o Medical Education Research Quality Instrument (MERSQI) e o LoE foi estabelecido de acordo com o Oxford Centre for Evidence-Based Medicine (OCEBM) adaptado pela Associação Européia de Cirurgia Endoscópica.

Resultados De todos os estudos incluídos nessa revisão, sete se referiam a simuladores validados. Estes receberam uma pontuação MERSQI média de 8,57 de 18 pontos possíveis. Nenhum dos estudos foi randomizado ou conduzido em ambiente de alta fidelidade. A melhor evidência foi fornecida pelos estudos com a placenta humana que recebeu uma pontuação $2 \mathrm{~b}$ e um grau de recomendação de 3 .

Conclusão Os simuladores brasileiros podem ser reproduzidos nos diferentes laboratórios disponíveis no país. O escore médio do MERSQI de estudos brasileiros é semelhante a pontuação média de estudos internacionais. Novos estudos devem buscar maior validação dos simuladores e maior nível de evidência com ensaios clínicos randomizados.

\section{Introduction}

The reduction of the working hours of residents in the United States and Europe has made simulation training a reality in all surgical specialties. ${ }^{1}$ Simulation allows residents to acquire a skill quicker and more safely before they go into the real scenario of the operating room. ${ }^{2} \mathrm{~A}$ recent meta-analysis has shown the benefits of simulation for motivated individuals who receive feedback for their performance. ${ }^{3}$

While simulation training has just started in Brazil and is taking its first steps, simulators in other countries are developing as new technologies are now emerging. Simulations are being done on synthetic models, using virtual reality and 3D printing, ${ }^{4-6}$ rather than human cadavers and live animals. There is now the possibility of pathology-specific training with an educational purpose and preoperative planning. ${ }^{7,8}$

Simulation training in neurosurgery has become even more important because one error can lead to devastating consequences for the patient. Kirkman et al demonstrated the benefits of simulation in the first systematic review of simulation in neurosurgery. ${ }^{9}$ However, most of the simulators demonstrated were expensive and so would be costly if they were used in Brazilian neurosurgery simulation laboratories.
The objectives of this systematic review are: 1 . To identify studies that describe simulation methods developed by Brazilian neurosurgeons. 2. To determine the quality of the study, the validation status, the level of evidence (LoE) and the degree of recommendation.

\section{Material and Methods}

This study was conducted by using the approved guidelines of the Preferred Reported Items for Systematic Reviews and Meta-Analysis (PRISMA). ${ }^{10}$

\section{Inclusion and Exclusion Criteria}

Articles describing validated and non-validated simulators for neurosurgical training were included in this review, while studies describing simulators for lumbar puncture, central venous access and rhizotomy procedures were excluded. Articles that were not written in either English or Portuguese were also excluded.

\section{Information Sources and Search}

A search in the databases at Medline, Scielo and Cochrane Library was performed and the studies took place between January 1, 1998, and September 29, 2018. The search terms 
used were "neurosurgery," "spine surgery" and "simulation training" as these were found to provide the largest number of articles. A more specific search was then performed afterwards using the terms "skill transfer," "skill retention," "motor performance" and "haptics." This allowed the researcher to find other supplementary studies.

\section{Studies Selection and Data Collection}

Articles approved in the inclusion criteria were submitted to evaluation of their abstracts, according to the PRISMA protocol. Duplicate papers, conference publications and articles that were not related to neurosurgery or surgery simulation were all excluded. The selected studies were submitted to a full-text evaluation. Articles that did not describe or validate simulators were also excluded. Studies with patient-specific planning simulators were considered simulators. Only studies by the main Brazilian authors were selected. The relevance tests were performed by two authors, and the study inclusion was done when consent had been obtained from both of them. When there was any disagreement, a third author defined the selection.

\section{Collected Data}

The data extracted from each study was categorized according to the type of simulator, the neurosurgical subspecialty addressed, the type of procedure, the validation of the simulator, the Medical Education Research Study Quality Instrument (MERSQI) ${ }^{11,12}$ ( - Table 1 ), and the (LoE of the study, according to the classification system of the Oxford Centre for Evidence-Based Medicine (OCEBM), adapted by the European Association of Endoscopic Surgery ${ }^{13,14}$ (-Table 2 and $\mathbf{3}$ ).

The simulators were categorized according to their neurosurgical subspecialty: vascular, functional, pediatric, spine, skull base, oncology, trauma, and basic neurosurgery. The results were then tabulated, and the simulators from each neurosurgical field grouped. The type of validation of the simulator was classified, according to the definitions of McDougall and Van Nortwick et $\mathrm{al}^{1}$ (-Fig. 1). All the studies were evaluated for the LoE, and the studies' quantitative analysis also received a MERSQI score.

\section{Results}

\section{Selected Articles}

Our search strategy found 512 articles. After the duplicates and articles that were not published in either English or Portuguese had been excluded, 494 remained for the screening of the title. After this stage, 191 articles were submitted to the abstract evaluation. Two authors agreed on the selection of 19 papers for a review of the full text version, out of which 15 were selected for inclusion in this systematic review (-Fig. 2).

\section{Characteristics of the Selected Studies}

The neurosurgery fields that had the largest number of simulation studies were the vascular and pediatric, with 4 (26.66\%) studies each. The most described simulator type was the human placenta (33.33\%), followed by 3D printed simulators (26.66\%), and the synthetic simulators (20\%). Only one study (6.66\%) reported the use of virtual or mixed reality. Eleven studies (73.33\%) had the resident's skill training as their main purpose and 4 (26.66\%) had patient-specific simulation. The most simulated neurosurgical procedure was ventricular neuroendoscopy (20\%). - Table 4 shows the relationship between the type of simulator that was used for each simulated procedure.

\section{Study Quality and Level of Evidence}

Of all the studies included in this review, 7 (46.66\%) referred to simulators that were validated. These studies were evaluated according to the MERSQI score and they presented an average score of 8.57 from 18 possible points (-Table 1). The studies with the highest scores were the models in the human placenta (MERSQI 12 to 8.5). No study was randomized to the control group. No studies were conducted in a high-fidelity environment. Only one study demonstrated the skill transfer from the simulator to the surgical center. ${ }^{15}$ The studies with the best evidence were the models in the human placenta, which received a score of $2 \mathrm{~b}$ and a degree of recommendation of 3 (-Table 5).

\section{Data Synthesis}

\section{Validated Simulation Models}

Of the 15 studies included in this systematic review, 7 (46.66\%) had at least 1 type of validation. The most used of these were construct and face validity, which occurred in 4 studies (57.14\%). Three studies (42.85\%) showed content validity, 2 (28.57\%) concurrent validity, and 1 (14.28\%) presented predictive validity. Vascular neurosurgery was the area that had the highest number of validated studies.

\section{Non-Validated Simulation Models}

Eight studies (53.33\%) were not validated. Four of them (50\%) were related to patient-specific simulation. A descriptive study using the placenta was subsequently validated in further studies. The area of pediatric neurosurgery was the one that presented the most non-validated studies (-Table 6).

\section{Vascular Neurosurgery}

Four studies were presented, with three of them being validated and one descriptive. The human placenta was the only type of simulator that was described for vascular neurosurgery simulation. It was used in the four mentioned studies. These studies received the highest scientific evidence and the highest MERSQI score. The descriptive study demonstrated the potential of the placenta for simulation in vascular neurosurgery ${ }^{16}$ (LoE-3, level of recommendation [LoR]-4). The study with the highest MERSQI score (12) used the placenta to demonstrate the transfer of skills that are acquired in the simulator to help with the neurosurgical procedure $^{15}$ (LoE $2 \mathrm{~b}$, LoR 3 ). The validated intracranialintracranial (IC-IC) bypass model presented the possibility 
300 Brazilian Neurosurgery Simulators Developed for Neurosurgical Training in Brazil Drummond-Braga et al.

Table 1 Medical Education Research Quality Instrument score for validated simulators

\begin{tabular}{|c|c|c|c|}
\hline $\begin{array}{l}\text { Items of the scale } \\
\text { (possible points) }\end{array}$ & Sub items of the scale (points if present) & $\begin{array}{l}\text { Number of } \\
\text { studies (\%) }\end{array}$ & Mean \\
\hline \multirow[t]{4}{*}{ Study design (3) } & Single group cross-sectional or single group posttest only (1) & $4(57)$ & 1.28 \\
\hline & Single group pretest and posttest (1.5) & $2(28)$ & \\
\hline & Nonrandomized, 2 groups (2) & $1(14)$ & \\
\hline & Randomized controlled trial (3) & 0.00 & \\
\hline \multirow[t]{9}{*}{ Sampling (3) } & Number of institutions studied: & & \\
\hline & $1(0.5)$ & $4(57)$ & 0.5 \\
\hline & $2(1)$ & $2(28)$ & \\
\hline & $3(1.5)$ & $1(14)$ & \\
\hline & Response rate, \%: & & \\
\hline & Not applicable & & \\
\hline & $<50$ or not reported $(0.5)$ & $7(100)$ & \\
\hline & $50-74(1)$ & 0.00 & \\
\hline & $>75(1.5)$ & 0.00 & \\
\hline \multirow[t]{2}{*}{ Type of data (3) } & Assessment by study participant (1) & $4(57)$ & 1.85 \\
\hline & Objective measurement (3) & $3(42)$ & \\
\hline \multirow{12}{*}{$\begin{array}{l}\text { Validity of evaluation } \\
\text { instrument (3) }\end{array}$} & Internal structure: & & \\
\hline & Not applicable & & \\
\hline & Not reported $(0)$ & $3(42)$ & 1.14 \\
\hline & Reported (1) & $4(57)$ & \\
\hline & Content: & & \\
\hline & Not applicable & & \\
\hline & Not reported (0) & $3(42)$ & \\
\hline & Reported (1) & $4(57)$ & \\
\hline & Relationships to other variables: & & \\
\hline & Not applicable & & \\
\hline & Not reported (0) & $3(42)$ & \\
\hline & Reported (1) & 0.00 & \\
\hline \multirow[t]{6}{*}{ Data analysis (3) } & Appropriateness of analysis: & & \\
\hline & Data analysis inappropriate for study design or type of data (0) & $3(42)$ & 2.57 \\
\hline & Data analysis appropriate for study design or type of data (1) & $4(57)$ & \\
\hline & Complexity of analysis: & & \\
\hline & Descriptive analysis only (1) & $3(42)$ & \\
\hline & Beyond descriptive analysis (2) & $4(57)$ & \\
\hline \multirow[t]{4}{*}{ Outcomes (3) } & Satisfaction, attitudes, perceptions, opinions, general facts (1) & $4(57)$ & 1.21 \\
\hline & Knowledge, skills $(1,5)$ & $3(42)$ & \\
\hline & Behaviors (2) & 0.00 & \\
\hline & Patient/health care outcome (3) & 0.00 & \\
\hline Total score & & & 8.57 \\
\hline
\end{tabular}

of performing several different bypass techniques ${ }^{17}$ (MERSQI 8.5, LoE $2 \mathrm{~b}$, LoR 3). The placenta was also used to demonstrate how useful it is in simulating endovascular procedures $^{18}$ (MERSQI 9.5, LoE 3, LoR 4).

\section{Pediatric Neurosurgery}

Four studies were presented for simulation in pediatric neurosurgery, but none of them were validated. Two studies were used for patient-specific simulation. Ghizoni et al 
Table 2 Modified levels of evidence classification for validation studies, adapted from the Oxford Centre for Evidence-Based Medicine classification by the European Association of Endoscopic Surgeons (Carter et al, 2005)

\begin{tabular}{|l|l|}
\hline $\begin{array}{l}\text { Level of } \\
\text { evidence }\end{array}$ & Criteria \\
\hline $1 \mathrm{a}$ & $\begin{array}{l}\text { Systematic reviews (meta-analysis) containing at } \\
\text { least some trial of level 1b evidence, in which } \\
\text { results of separate, independently controlled trials } \\
\text { are consistent }\end{array}$ \\
\hline $1 \mathrm{~b}$ & $\begin{array}{l}\text { Randomized controlled trial of good quality and of } \\
\text { adequate sample size (power calculations) }\end{array}$ \\
\hline $2 \mathrm{a}$ & $\begin{array}{l}\text { Randomized trials of reasonable quality and/or of } \\
\text { inadequate sample size }\end{array}$ \\
\hline $2 \mathrm{~b}$ & $\begin{array}{l}\text { Nonrandomized trials, comparative research } \\
\text { (parallel cohort) }\end{array}$ \\
\hline $2 \mathrm{c}$ & $\begin{array}{l}\text { Nonrandomized trials, comparative research } \\
\text { (historical cohort, literature controls) }\end{array}$ \\
\hline 3 & $\begin{array}{l}\text { Nonrandomized, non-comparative trials, } \\
\text { descriptive research }\end{array}$ \\
\hline 4 & $\begin{array}{l}\text { Expert opinions, including the opinion of Work } \\
\text { Group members }\end{array}$ \\
\hline
\end{tabular}

Table 3 Levels of recommendation for training models, adapted from the Oxford Centre for Evidence-Based Medicine Classification by the European Association of Endoscopic Surgeons (Carter et al, 2005)

\begin{tabular}{|l|l|}
\hline $\begin{array}{l}\text { Level of } \\
\text { evidence }\end{array}$ & Criteria \\
\hline 1 & $\begin{array}{l}\text { Based on one systematic review (1a) or at least two } \\
\text { independently conducted research projects } \\
\text { classified as 1b }\end{array}$ \\
\hline 2 & $\begin{array}{l}\text { Based on at least two independently conducted } \\
\text { research projects classified as level 2a or 2b, within } \\
\text { concordance }\end{array}$ \\
\hline 3 & $\begin{array}{l}\text { Based on one independently conducted research } \\
\text { project level 2b, or at least two trials of level 3, } \\
\text { within concordance }\end{array}$ \\
\hline 4 & $\begin{array}{l}\text { Based on one trial at level 3 or multiple expert } \\
\text { opinions, including the opinions of Work Group } \\
\text { members (e.g., level 4) }\end{array}$ \\
\hline
\end{tabular}

demonstrated the use of 3D printing in both planning and preoperative simulation in three cases of craniosynostosis. ${ }^{19}$ Coelho et al performed the patient-specific simulation for an encephalocele on the face using a multimaterial 3D print. This was later replicated in surgery. ${ }^{20}$

Coelho et al presented two studies with the same simulator (ASPEN) that was developed for the simulation of craniosynostosis and ventricular neuroendoscopy. ${ }^{21,22}$ The studies of pediatric neurosurgery were evaluated with a LoE of 3 e a LoR of 4.

\section{Neurosurgical Oncology}

Two studies were included with simulators to remove brain tumors. Both of these simulators were validated. Oliveira et al described the use of the human placenta to simulate microsurgery for an intracranial tumor. ${ }^{23}$ (MERSQI 9.5, LoE 2b, LoR 3 ). Filho et al described and validated a synthetic simulator called Sinus Model Oto-Rhino Neuro Trainer(S.I.M.O.N.T. ${ }^{24}$ for the simulation of neuroendoscopy for the resection of a ventricular tumor (MERSQI 9.5, LoE 2b, LoR 3) and access to the base of the skull.

\section{Spine}

Two simulators were described for the spine. One simulator underwent validation and the other was a patient-specific simulation description. Coelho et al described and validated a simulator to perform lumbar spine procedures, such as arthrodesis and laminectomy. ${ }^{25}$ They used the mixed reality that combines virtual reality with the synthetic model (MERSQI 5.5, LoE 3, LoR 4). Paiva et al described the patientspecific simulation with a $3 \mathrm{D}$ printed model for surgical planning of a corpectomy and removal of a complex tumor in the cervical spine ${ }^{26}$ (LoE 3, LoR 4).

\section{Basic Neurosurgery}

There was no validation for any of the three studies that were related to the basic procedures of neurosurgery. Drummond-Braga et al described the use of a coconut fruit as a simulator for cerebrospinal fluid leak avoidance during craniotomy for residents of the first year. ${ }^{27}$ Ferreira et al described a method that is used for dilation of the ventricular system in cadavers to simulate ventricular endoscopy. ${ }^{28}$ Grillo et al presented the creation of a phantom used

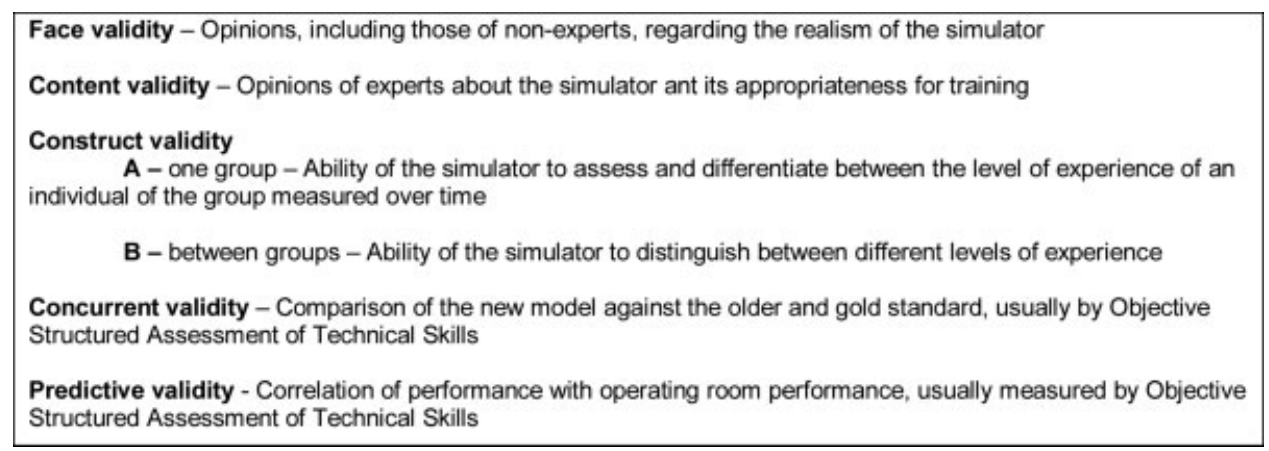

Fig. 1 Types of validity. Definitions from McDougall et al; van Nortwick et al. ${ }^{30,31}$ Translated by Aydin et al. ${ }^{1}$ Current Status of Simulation and Training Models in Urological Surgery: A Systematic Review. DOI: 10.1016/j.juro.2016.01.131. 
302 Brazilian Neurosurgery Simulators Developed for Neurosurgical Training in Brazil Drummond-Braga et al.
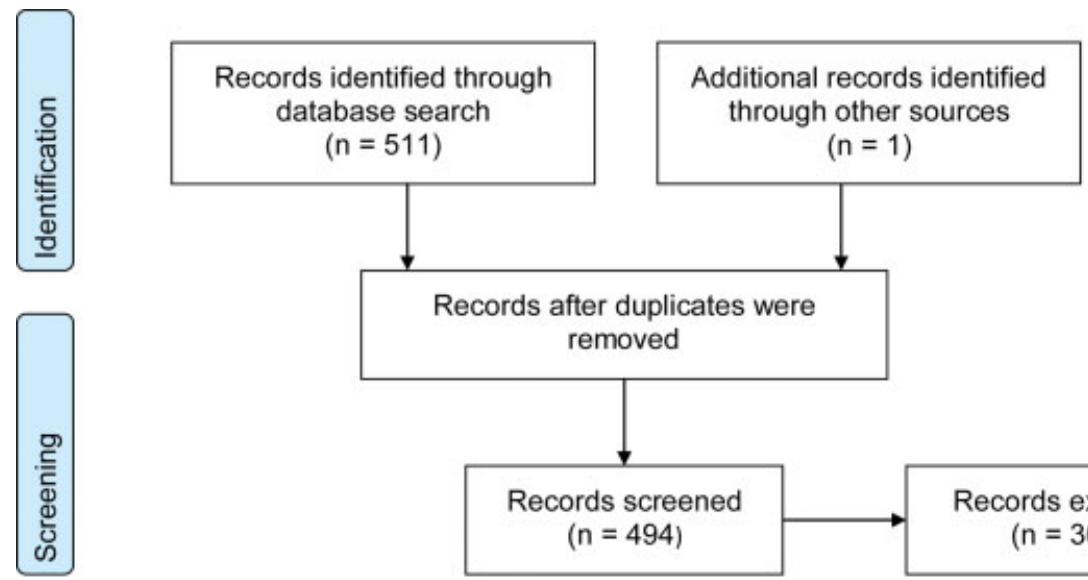

Records after duplicates were removed
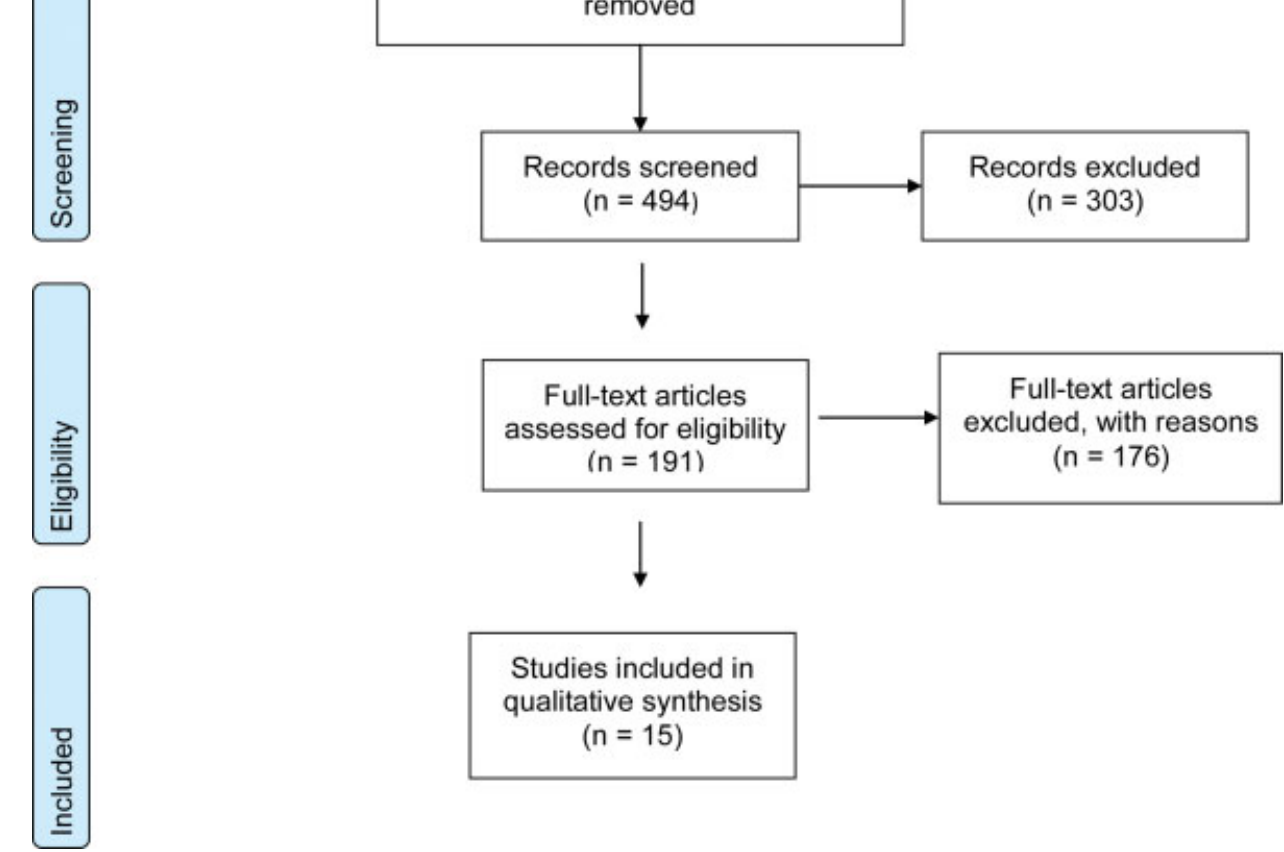

Fig. 2 Preferred Reported Items for Systematic Reviews and Meta-Analysis flow diagram.

Table 4 Type of simulator used for training in each neurosurgical procedure

\begin{tabular}{|c|c|c|c|c|c|c|c|}
\hline Subspeciality & Procedure & $\begin{array}{l}\text { Human } \\
\text { Placenta }\end{array}$ & $\begin{array}{l}\text { Synthetic } \\
\text { Model }\end{array}$ & $\begin{array}{l}\text { 3D } \\
\text { Printing }\end{array}$ & $\begin{array}{l}\text { Mixed } \\
\text { Reality }\end{array}$ & Corpse & Fruit \\
\hline \multirow[t]{4}{*}{ Neurovascular } & Vascular microsurgery & $\mathrm{x}$ & & & & & \\
\hline & Intracranial bypass & $\mathrm{x}$ & & & & & \\
\hline & Angiography/ Endovascular & $x$ & & & & & \\
\hline & Microsurgery aneurysm & $\mathrm{x}$ & & & & & \\
\hline \multirow[t]{3}{*}{ Neuropediatric } & Neuroendoscopy & & $x$ & & & & \\
\hline & Craniosynostosis & & $x$ & $x$ & & & \\
\hline & Meningocele & & & $x$ & & & \\
\hline \multirow[t]{2}{*}{ Neuroncology } & Microsurgery for tumor & $x$ & & & & & \\
\hline & Neuroendoscopy & & $x$ & & & & \\
\hline \multirow[t]{2}{*}{ Spine } & Arthrodesis & & & & $x$ & & \\
\hline & Corpectomy & & & $x$ & & & \\
\hline \multirow{3}{*}{$\begin{array}{l}\text { Basic } \\
\text { Neurosurgery }\end{array}$} & Craniotomy & & & & & & $x$ \\
\hline & Anatomy & & & $x$ & & & \\
\hline & $\begin{array}{l}\text { External ventricular } \\
\text { drain/neuroendoscopy }\end{array}$ & & & & & $\mathrm{x}$ & \\
\hline
\end{tabular}


Table 5 Level of evidence of validated studies

\begin{tabular}{|l|l|l|l|l|l|}
\hline Author & MERSQI & LoE & LoR & Simulated Procedure & Type of Validation \\
\hline Oliveira M. M. R. 2018 & 12 & 2b & 3 & Aneurysm clipping & Predictive and competition \\
\hline Oliveira M. M. R. 2018 & 8.5 & $2 \mathrm{~b}$ & 3 & Bypass & Competition and construct \\
\hline Oliveira M. M. R. 2015 & 9.5 & 3 & 4 & Endovascular & Construct, content and face \\
\hline Oliveira M. M. R. 2014 & 9.5 & $2 \mathrm{~b}$ & 3 & Microsurgery tumor & Construct, content and face \\
\hline Grillo F. W., 2018 & 5.5 & 4 & 4 & Craniotomy & Content \\
\hline Filho F. V. 2011 & 9.5 & $2 \mathrm{~b}$ & 3 & Neuroendoscopy & Construct and face \\
\hline Coelho, G. 2018 & 5.5 & 3 & 4 & Arthrodesis & Construct and face \\
\hline
\end{tabular}

Abbreviations: LoE, level of evidence; LoR, level of recommendation; MERSQI, Medical Education Research Study Quality Instrument.

Table 6 Level of evidence of non-validated studies

\begin{tabular}{|l|l|l|l|}
\hline Author & LoE & LoR & Simulated procedure \\
\hline Coelho, G. 2014 & 3 & 4 & Neuroendoscopy \\
\hline Ghizoni E. 2017 & 3 & 4 & Craniosynostosis \\
\hline Oliveira M. M. R. 2014 & 2b & 3 & Vascular microsurgery \\
\hline Paiva W. S. 2007 & 3 & 4 & Spine tumor \\
\hline Coelho G., 2014 & 3 & 4 & Craniosynostosis \\
\hline Ferreira C. D., 2014 & 3 & 4 & Neuroendoscopic \\
\hline Coelho, G. 2017 & 3 & 4 & Meningocele \\
\hline Drummond-Braga B. 2016 & 3 & 4 & Craniotomy \\
\hline
\end{tabular}

Abbreviations: LoE, level of evidence; LoR, level of recommendation.

for neurosurgical training and preoperative planning. ${ }^{29}$ All the studies in this area were classified according to their LoE, which was 3, and the LoR, which was 4. - Table 7 shows a summary of each study's main characteristics.

\section{Discussion}

The Brazilian studies that underwent validation presented an average score of 8.56 points in the MERSQI. This value approximates the score described in the systematic review by Kirkman et al in 2014 (9.21 points). ${ }^{8}$ The worst scores were received by validation topics that related to study designs and the number of institutions involved.

Few of the studies on simulation were able to demonstrate the transfer of skills from the simulator to the surgical room. ${ }^{2}$ However, in 2018, Oliveira et al were able to demonstrate the transfer of an acquired ability in simulations of vascular microsurgery in the placenta to the real scenario in aneurysm surgeries. It was the only Brazilian study that described predictive validity. ${ }^{15}$

The highest LoE found was $2 b$ and the best grade of recommendation was 3 . This demonstrates the lack of a randomized blind study in Brazilian simulators. When analyzed in conjunction with the MERSQI score, the indication is that further Brazilian studies in simulation should be performed that search for randomization with control groups and multicentric studies.

The majority of the studies were of vascular and pediatric subspecialties. The most simulated procedures had the greatest demand for manual skills, such as vascular microsurgery and recent technological evolution, such as ventricular endoscopy. The least frequently simulated were functional neurosurgery and neurotrauma.

Among the non-validated simulators, the use of patientspecific or pathology-specific simulators is noteworthy. These simulators were used to provide education about specific conditions found in neurosurgery, as well as preoperative planning and rehearsal in complex cases. Three-dimensional printing was the most described type of simulation used for this purpose. Craniosynostosis surgery was the most simulated patient-specific procedure described.

This systematic review had its limitations. The main ones being the different forms of methodology of each study, and the different groups of evaluated participants and heterogeneous simulators. Perhaps the greatest limitation was the difference in the quality of the studies and the fact that most simulators lack a validation instrument.

Future research should focus on the creation of highfidelity simulators that are accessible to the resident physician and could be introduced to neurosurgical training 


\begin{tabular}{|c|c|c|c|c|c|}
\hline & 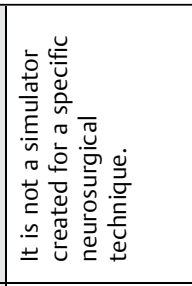 & 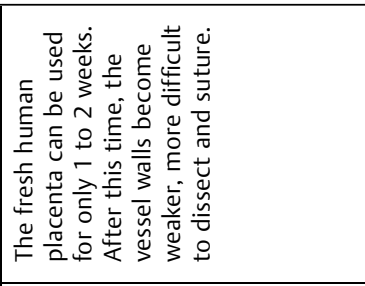 & 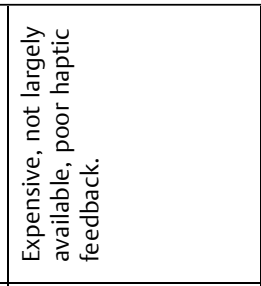 & 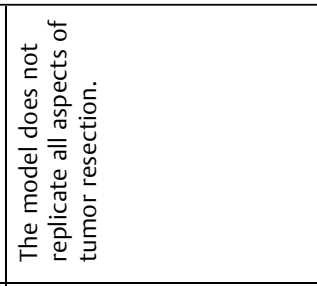 & 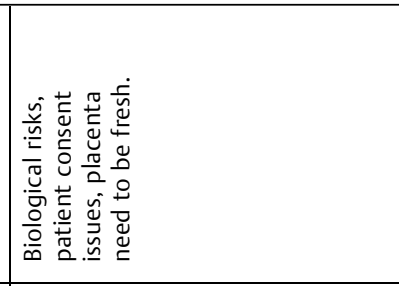 \\
\hline 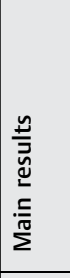 & 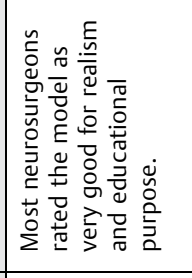 & 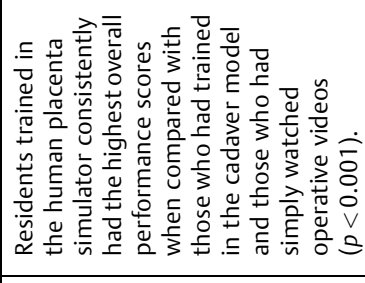 & 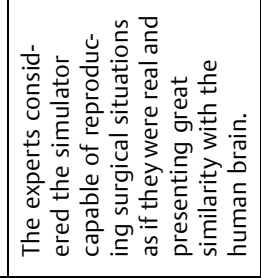 & 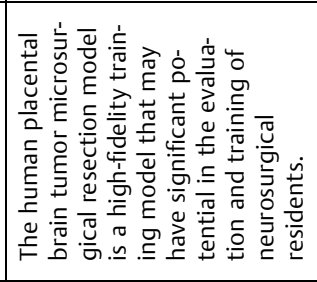 & 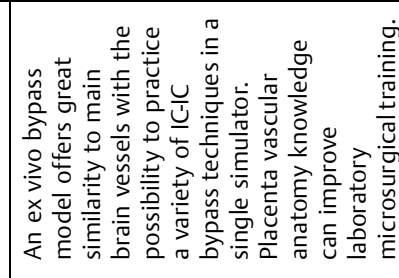 \\
\hline 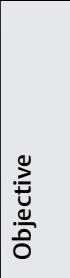 & 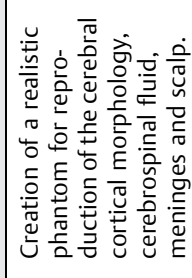 & 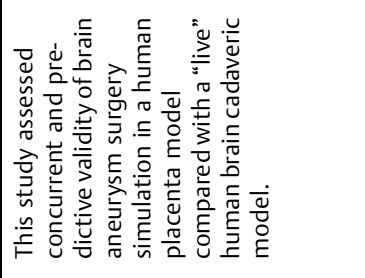 & 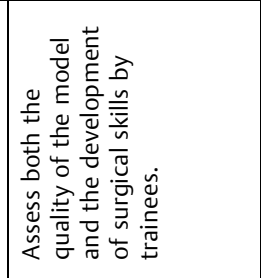 & 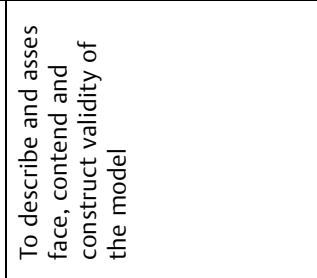 & 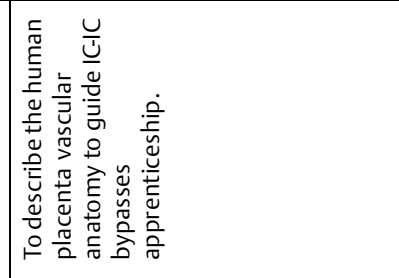 \\
\hline & 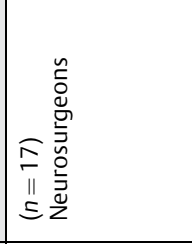 & 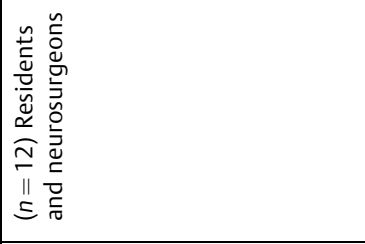 & 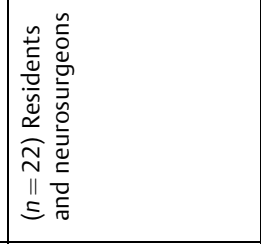 & 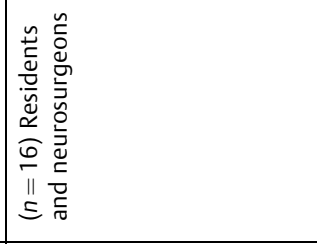 & 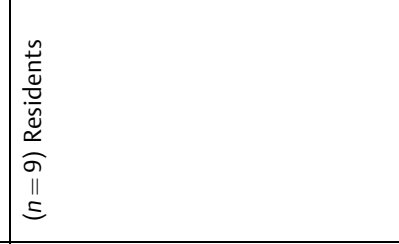 \\
\hline 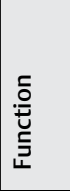 & 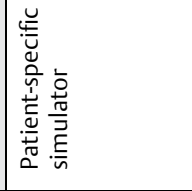 & 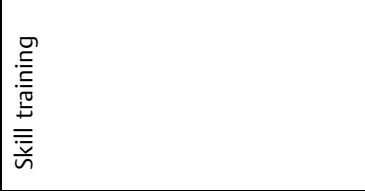 & 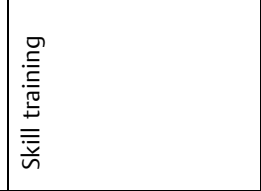 & 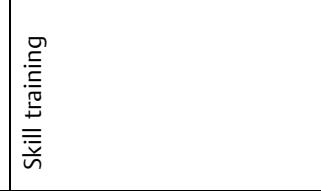 & 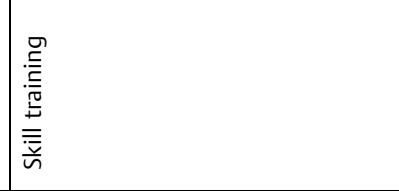 \\
\hline 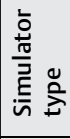 & 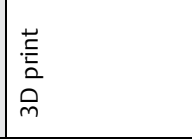 & 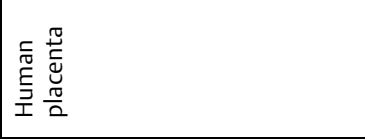 & 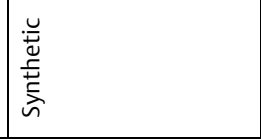 & 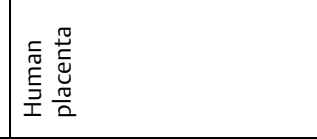 & 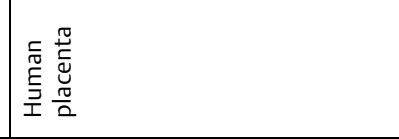 \\
\hline & 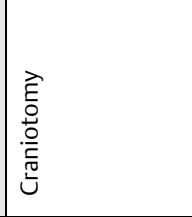 & 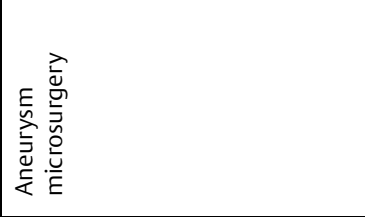 & 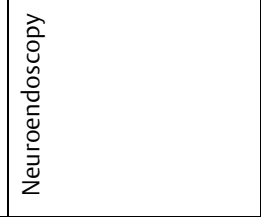 & 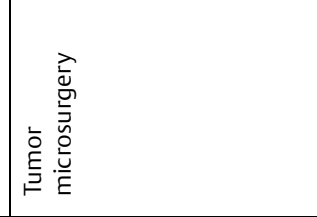 & 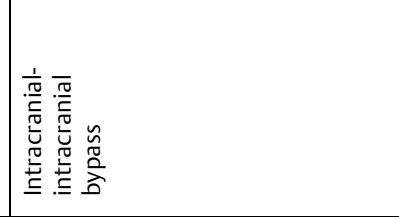 \\
\hline 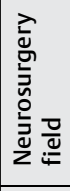 & 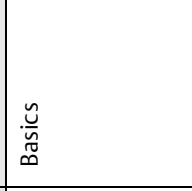 & 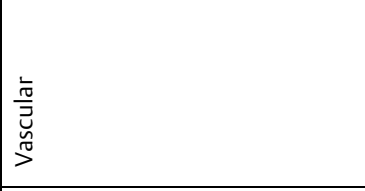 & 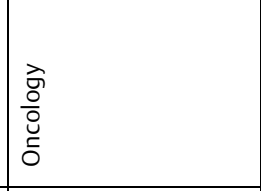 & 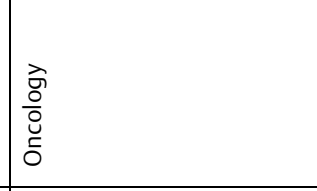 & 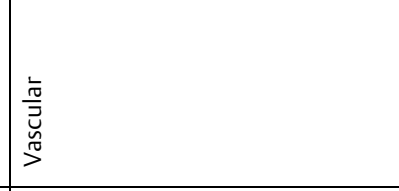 \\
\hline 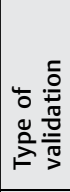 & 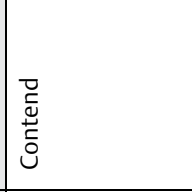 & 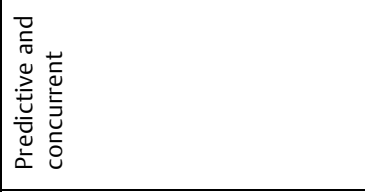 & 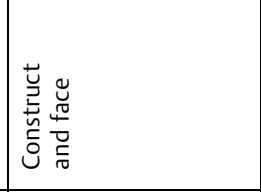 & 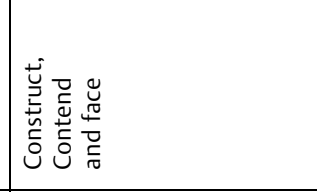 & 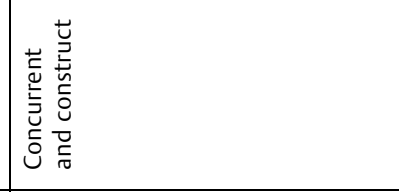 \\
\hline \begin{tabular}{|l}
$\frac{3}{3}$ \\
$\frac{3}{50}$ \\
$\frac{5}{5}$
\end{tabular} & $\stackrel{\check{u}}{\rightleftharpoons}$ & $\stackrel{\check{\nu}}{\rightleftharpoons}$ & $\stackrel{\check{u}}{\rightleftharpoons}$ & 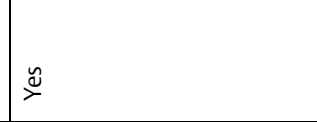 & 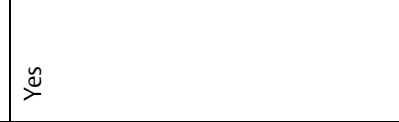 \\
\hline 呈 & 号 & 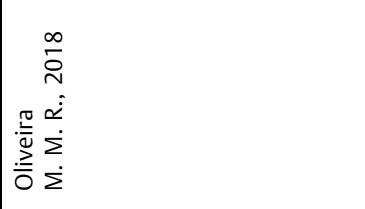 & 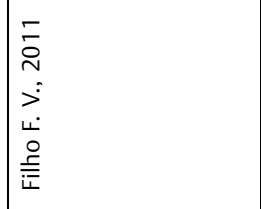 & 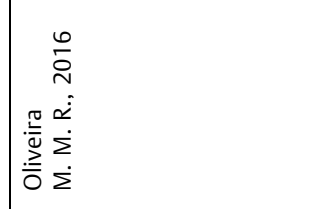 & 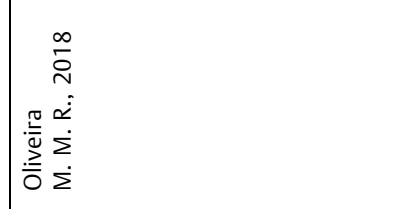 \\
\hline
\end{tabular}




\begin{tabular}{|c|c|c|c|c|c|}
\hline 蒿 & 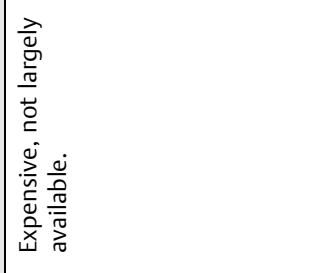 & 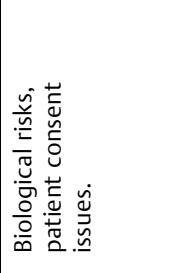 & 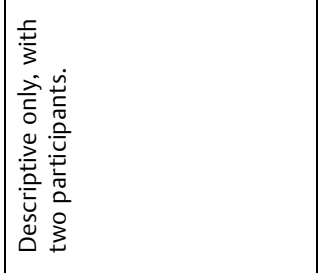 & 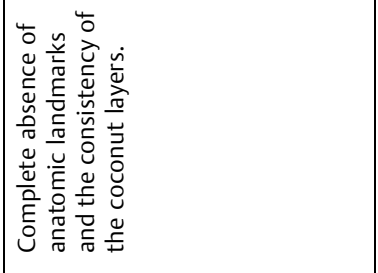 & 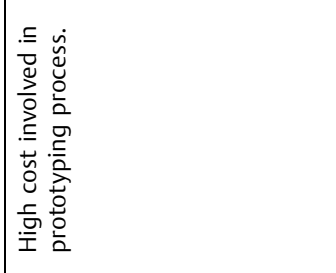 \\
\hline 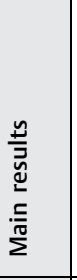 & 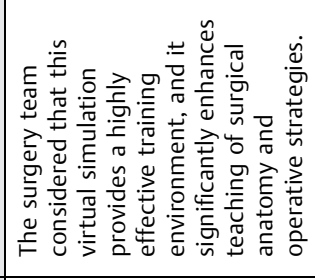 & 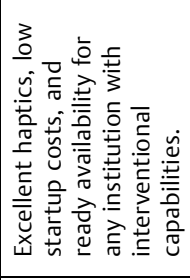 & 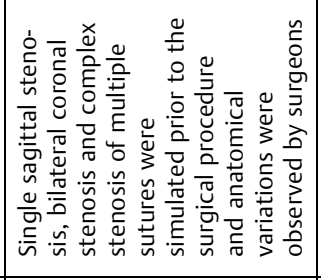 & 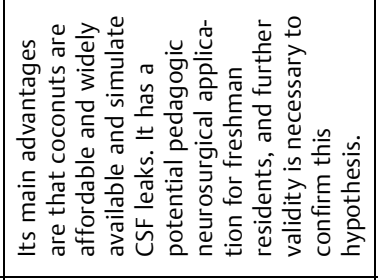 & 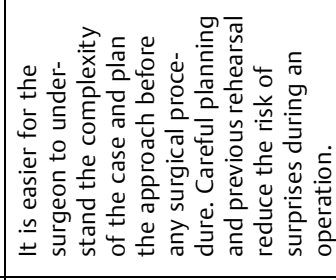 \\
\hline 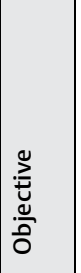 & 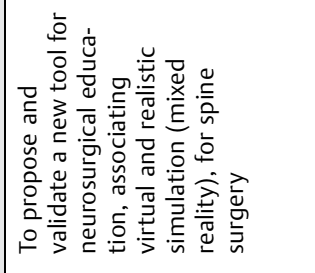 & 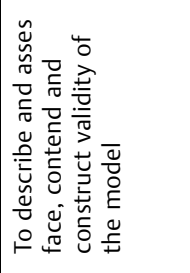 & 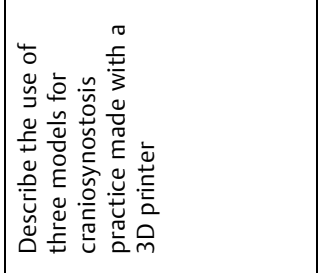 & 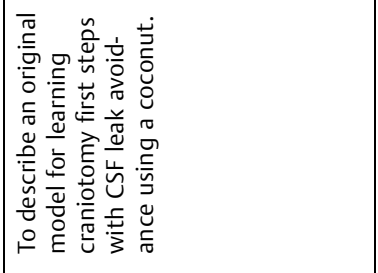 & 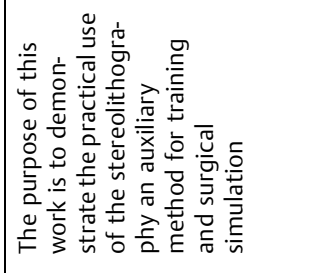 \\
\hline 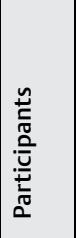 & 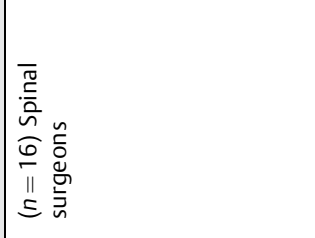 & 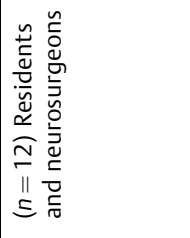 & 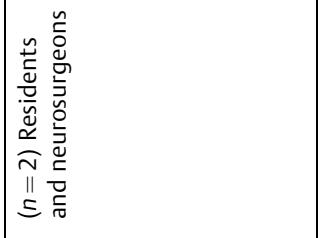 & $\frac{s}{z}$ & $\frac{\mathbb{z}}{z}$ \\
\hline 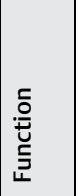 & 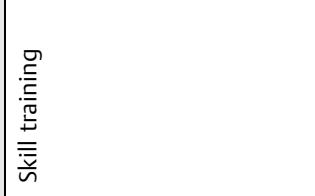 & 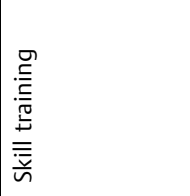 & 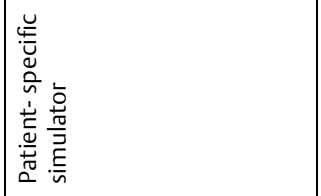 & 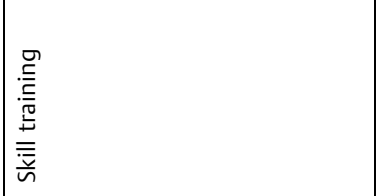 & 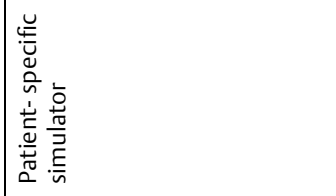 \\
\hline 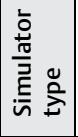 & 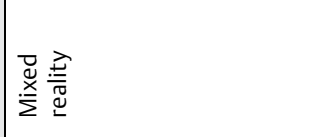 & 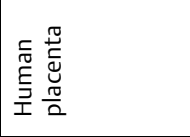 & $\begin{array}{l}\text { 䓂 } \\
\text { 竞 } \\
\text { m }\end{array}$ & 泀 & 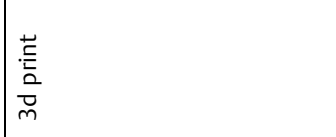 \\
\hline 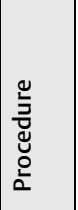 & 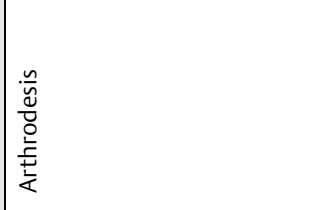 & 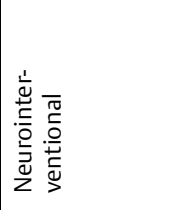 & 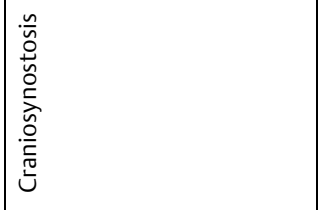 & 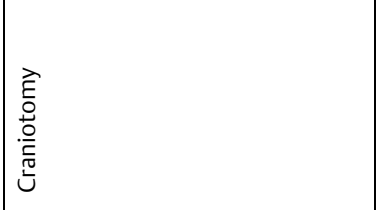 & 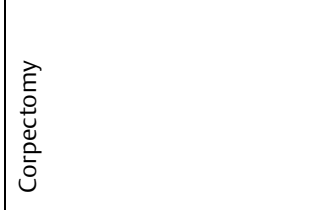 \\
\hline 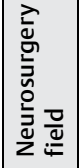 & 䒿 & 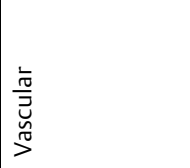 & 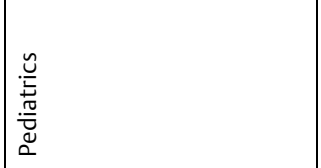 & 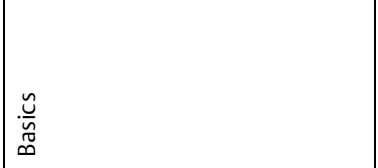 & 竞 \\
\hline 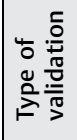 & 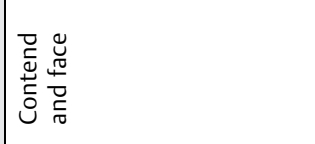 & 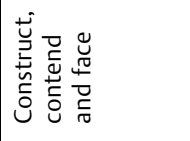 & $\frac{\leqslant}{z}$ & 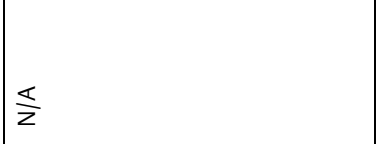 & $\frac{\mathbb{z}}{z}$ \\
\hline 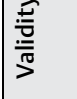 & $\stackrel{\varrho}{\rightleftharpoons}$ & $\stackrel{\breve{u}}{\rightleftharpoons}$ & z & z & 2 \\
\hline 亮 & 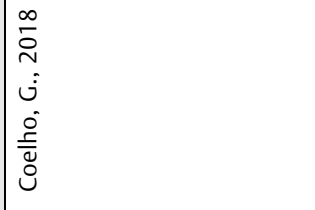 & 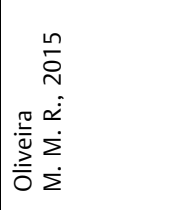 & 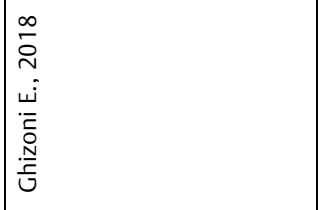 & 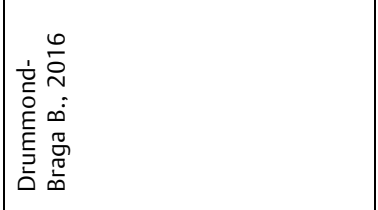 & 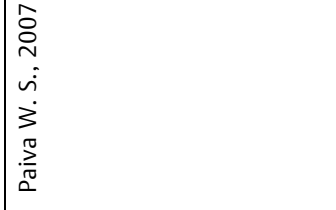 \\
\hline
\end{tabular}




\begin{tabular}{|c|c|c|c|c|c|}
\hline 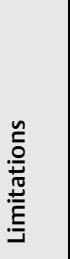 & 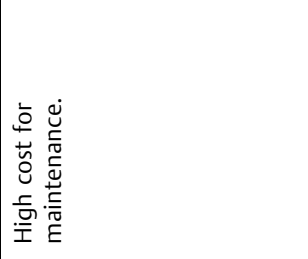 & 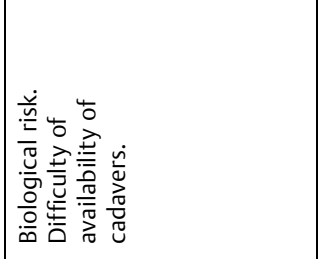 & 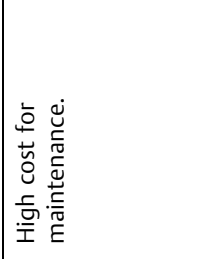 & 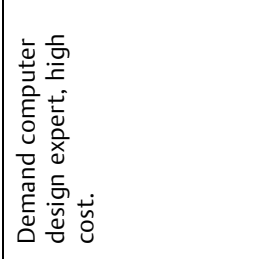 & 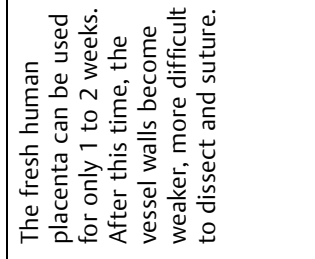 \\
\hline 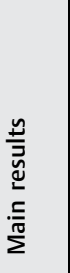 & 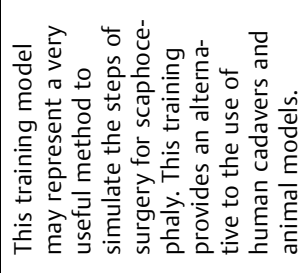 & 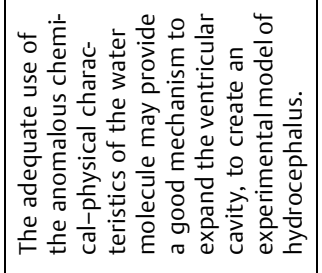 & 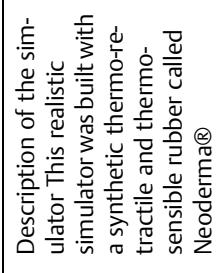 & 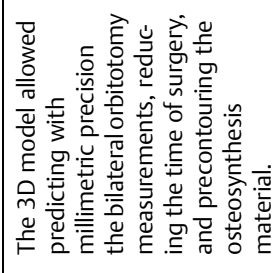 & 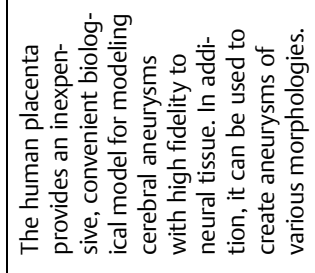 \\
\hline 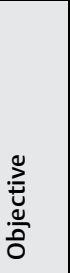 & 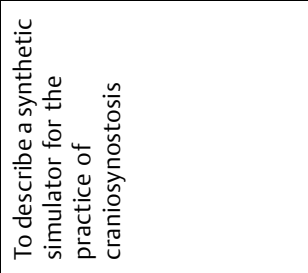 & 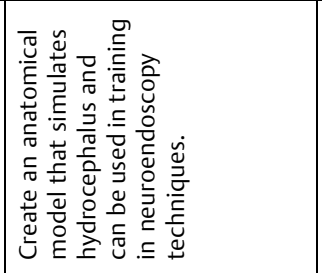 & 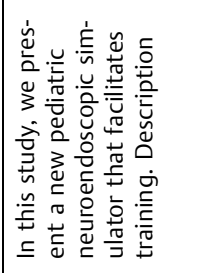 & 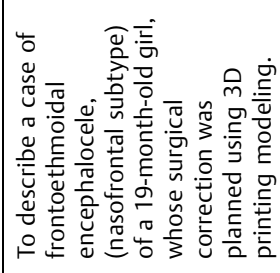 & 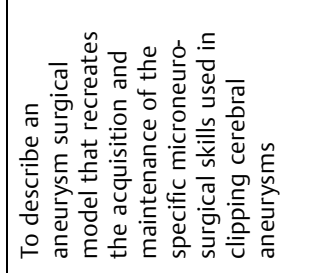 \\
\hline 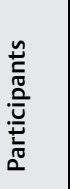 & $\frac{\pi}{z}$ & $\frac{\pi}{z}$ & $\frac{\pi}{z}$ & $\frac{\pi}{z}$ & $\frac{\pi}{z}$ \\
\hline 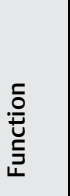 & 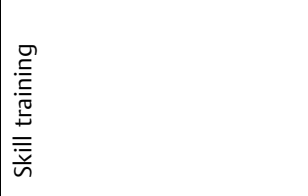 & 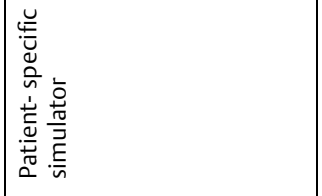 & 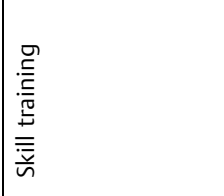 & 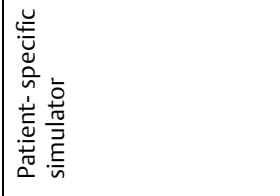 & 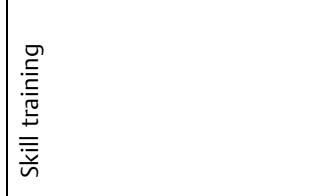 \\
\hline 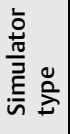 & 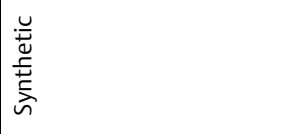 & 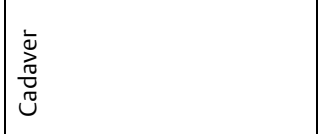 & 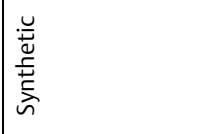 & 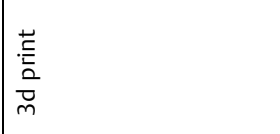 & 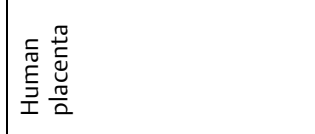 \\
\hline 这 & 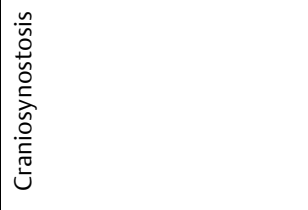 & 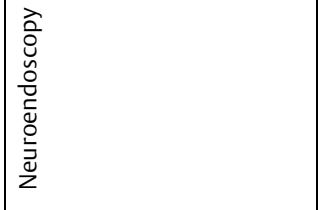 & 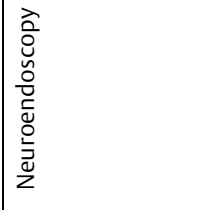 & 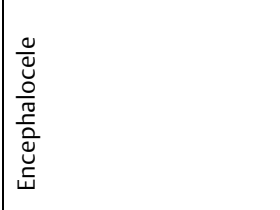 & 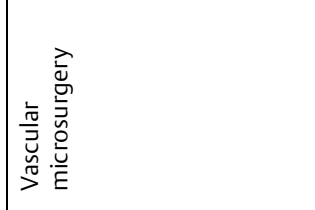 \\
\hline 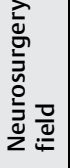 & 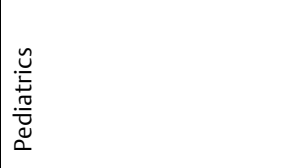 & 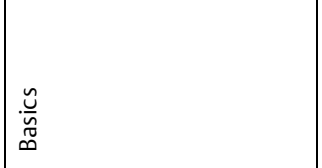 & 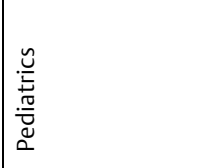 & 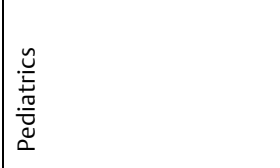 & 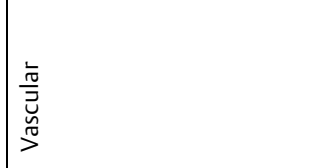 \\
\hline 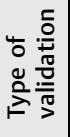 & $\frac{\pi}{z}$ & $\frac{s}{z}$ & $\frac{s}{z}$ & $\frac{\pi}{z}$ & $\frac{\pi}{z}$ \\
\hline 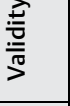 & z & 2 & 2 & 㝏 & $\frac{0}{z}$ \\
\hline $\begin{array}{l}\text { 高 } \\
\frac{1}{z}\end{array}$ & 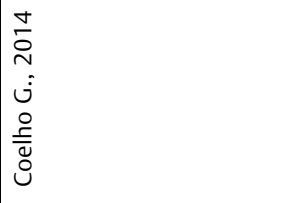 & 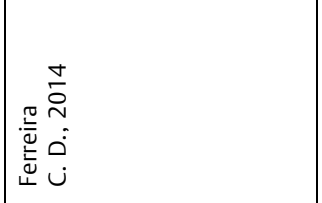 & 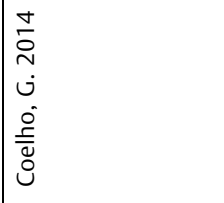 & 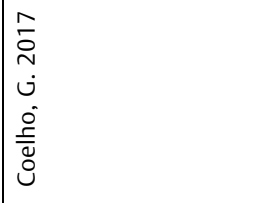 & 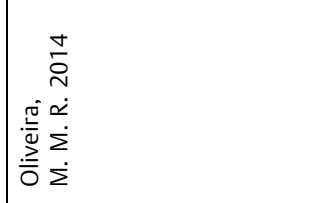 \\
\hline
\end{tabular}


laboratories throughout Brazil. Further validated and randomized studies should be performed to define the ideal simulators that could truly fit in every level of Brazil's residency skill training program.

\section{Conclusion}

The MERSQI score of the Brazilian studies resembles the international average. The LoE and the degree of recommendation of most of the published articles is still low. New studies should pursue a further validation of the simulators and hold randomized trials with a control group. There is a lot of creativity, simplicity and technology involved in Brazilian simulators. Most of them can be reproduced at the skill training laboratories that are available in the country.

\section{Conflict of Interest}

None declared.

\section{References}

1 Aydin A, Shafi AM, Shamim Khan M, Dasgupta P, Ahmed K. Current Status of Simulation and Training Models in Urological Surgery: A Systematic Review. J Urol 2016;196(02):312-320

2 Rehder R, Abd-El-Barr M, Hooten K, Weinstock P, Madsen JR, Cohen AR. The role of simulation in neurosurgery. Childs Nerv Syst 2016;32(01):43-54

3 McGaghie WC, Issenberg SB, Cohen ER, Barsuk JH, Wayne DB. Does simulation-based medical education with deliberate practice yield better results than traditional clinical education? A metaanalytic comparative review of the evidence. Acad Med 2011;86 (06):706-711

4 Loh CYY, Wang AYL, Tiong VTY, et al. Animal models in plastic and reconstructive surgery simulation-a review. JSurg Res 2018; 221:232-245

5 Pfandler M, Lazarovici M, Stefan P, Wucherer P, Weigl M. Virtual reality-based simulators for spine surgery: a systematic review. Spine J 2017;17(09):1352-1363

6 Vakharia VN, Vakharia NN, Hill CS. Review of 3-Dimensional Printing on Cranial Neurosurgery Simulation Training. World Neurosurg 2016;88:188-198

7 Ryu WHA, Dharampal N, Mostafa AE, et al. Systematic Review of Patient-Specific Surgical Simulation: Toward Advancing Medical Education. J Surg Educ 2017;74(06):1028-1038

8 Dawe SR, Pena GN, Windsor JA, et al. Systematic review of skills transfer after surgical simulation-based training. Br J Surg 2014; 101(09):1063-1076

9 Kirkman MA, Ahmed M, Albert AF, Wilson MH, Nandi D, Sevdalis $\mathrm{N}$. The use of simulation in neurosurgical education and training. A systematic review. J Neurosurg 2014;121(02):228-246

10 Moher D, Liberati A, Tetzlaff J, Altman DG, Group P; PRISMA Group. Preferred reporting items for systematic reviews and meta-analyses: the PRISMA statement. PLoS Med 2009;6(07): e1000097

11 Reed DA, Cook DA, Beckman TJ, Levine RB, Kern DE, Wright SM. Association between funding and quality of published medical education research. JAMA 2007;298(09):1002-1009

12 Cook DA, Reed DA. Appraising the quality of medical education research methods: the Medical Education Research Study Quality
Instrument and the Newcastle-Ottawa Scale-Education. Acad Med 2015;90(08):1067-1076

13 Carter FJ, Schijven MP, Aggarwal R, et al. Consensus guidelines for validation of virtual reality surgical simulators. Simul Healthc 2006;1(03):171-179

14 Morgan M, Aydin A, Salih A, Robati S, Ahmed K. Current Status of Simulation-based Training Tools in Orthopedic Surgery: A Systematic Review. J Surg Educ 2017;74(04):698-716

15 de Oliveira MMR, Ferrarez CE, Ramos TM, et al. Learning brain aneurysm microsurgical skills in a human placenta model: predictive validity. J Neurosurg 2018;128(03):846-852

16 Oliveira Magaldi M, Nicolato A, Godinho JV, et al. Human placenta aneurysm model for training neurosurgeons in vascular microsurgery. Neurosurgery 2014;10(Suppl 4):592-600, discussion 600-601

17 Oliveira MM, Wendling L, Malheiros JA, et al. Human Placenta Simulator for Intracranial-Intracranial Bypass: Vascular Anatomy and 5 Bypass Techniques. World Neurosurg 2018;119:e694-e702

18 Ribeiro de Oliveira MM, Nicolato A, Santos M, et al. Face, content, and construct validity of human placenta as a haptic training tool in neurointerventional surgery. J Neurosurg 2016;124(05): $1238-1244$

19 Ghizoni E, de Souza JPSAS, Raposo-Amaral CE, et al. 3D-Printed Craniosynostosis Model: New Simulation Surgical Tool. World Neurosurg 2018;109:356-361

20 Coelho G, Chaves TMF, Goes AF, Del Massa EC, Moraes O, Yoshida M. Multimaterial 3D printing preoperative planning for frontoethmoidal meningoencephalocele surgery. Childs Nerv Syst 2018;34(04):749-756

21 Coelho G, Zymberg S, Lyra M, Zanon N, Warf B. New anatomical simulator for pediatric neuroendoscopic practice. Childs Nerv Syst 2015;31(02):213-219

22 Coelho G, Warf B, Lyra M, Zanon N. Anatomical pediatric model for craniosynostosis surgical training. Childs Nerv Syst 2014;30(12): 2009-2014

23 Oliveira MM, Araujo AB, Nicolato A, et al. Face, Content, and Construct Validity of Brain Tumor Microsurgery Simulation Using a Human Placenta Model. Oper Neurosurg (Hagerstown) 2016;12 (01):61-67

24 Filho FV, Coelho G, Cavalheiro S, Lyra M, Zymberg ST. Quality assessment of a new surgical simulator for neuroendoscopic training. Neurosurg Focus 2011;30(04):E17

25 Coelho G, Defino HLA. The Role of Mixed Reality Simulation for Surgical Training in Spine: Phase 1 Validation. Spine 2018;43(22): 1609-1616

26 Paiva WS, Amorim R, Bezerra DA, Masini M. Aplication of the stereolithography technique in complex spine surgery. Arq Neuropsiquiatr 2007;65(2B):443-445

27 Drummond-Braga B, Peleja SB, Macedo G, et al. Coconut Model for Learning First Steps of Craniotomy Techniques and Cerebrospinal Fluid Leak Avoidance. World Neurosurg 2016;96:191-194

28 Ferreira CD, Matushita H, Silva BR, et al. Proposal of a new method to induce ventricular system dilation to simulate the features of hydrocephalus and provide an anatomical model for neuroendoscopy training. Childs Nerv Syst 2014;30(07):1209-1215

29 Grillo FW, Souza VH, Matsuda RH, et al. Patient-specific neurosurgical phantom: assessment of visual quality, accuracy, and scaling effects. 3D Print Med 2018;4(01):3

30 McDougall EM. Validation of surgical simulators. J Endourol 2007; 21(03):244-247

31 Van Nortwick SS, Lendvay TS, Jensen AR, et al. Methodologies for establishing validity in surgical simulation studies. Surgery 2010; 147(05):622-630 